\title{
Pneumonectomy for empyema
}

\author{
Marko Kostic ${ }^{1}$, Jean-Marc Baste ${ }^{2}$ \\ ${ }^{1}$ Serbia and Montenegro, Clinic for Thoracic Surgery, Clinical Centre of Serbia, Belgrade, Serbia; ${ }^{2}$ Department of General and Thoracic Surgery, \\ UNIROUEN, Inserm U1096, Rouen University Hopsital, Normandie University, Rouen, France \\ Contributions: (I) Conception and design: All authors; (II) Administrative support: All authors; (III) Provision of study material or patients: All authors; \\ (IV) Collection and assembly of data: All authors; (V) Data analysis and interpretation: All authors; (VI) Manuscript writing: All authors; (VII) Final \\ approval of manuscript: All authors. \\ Correspondence to: Marko Kostic. Serbia and Montenegro, Clinic for Thoracic Surgery, Clinical Centre of Serbia, Belgrade, Serbia. \\ Email: kostmarko@gmail.com.
}

\begin{abstract}
Pneumonectomy for chronic lung infections and consecutive empyema has been averted because of the potential intraoperative and postoperative complications. In this analysis we have evaluated 10 prominent articles targeting mortality and morbidity outcome. Mortality rate were from 1.2-24.6\% and morbidity were from 11.9-53\%. Complications like postoperative empyema, bronchopleural fistula (BF) and postoperative bleeding affects the prognosis, also technique and operative duration. The surgical technique is of the paramount significance to reduce postoperative morbidity and mortality in this high risk operation. Pneumonectomy for empyema should be left to be a treatment alternative only for carefully selected patients.
\end{abstract}

Keywords: Morbidity; mortality; pneumonectomy; empyema

Received: 17 March 2020; Accepted: 04 June 2020; Published: 10 April 2021.

doi: 10.21037/shc-20-62

View this article at: http://dx.doi.org/10.21037/shc-20-62

\section{Introduction}

In the year 1895, was performed the first pneumonectomy in patient with tuberculosis and empyema. Additional tentatives with one stage pneumonectomy were unsuccessful. Kummel has done a pneumonectomy for lung cancer by clamping the pedicle and leaving the clamps in situ, in 1910 ; on the $6^{\text {th }}$ postoperative day the patient died. In 1922, Hinz achieved the first separate hilar ligation; the patient passed away from heart failure on the $3^{\text {rd }}$ operative day. Further, in 1930 Churchill, in 1931 Archibald, and in 1933 Ivanissevich pursued extirpation of a whole lung with no survivor beyond a few days. In Berlin, in 1930, has been performed the first left-sided pneumonectomy in Europe, as a two-stage procedures, by Rudolf Nissen. The first effective en bloc left pneumonectomy, for lung cancer, was reported by Graham and Singer in 1933. The first successful en bloc right pneumonectomy, for carcinoid tumor, was performed by Overholt in 1935 (1). Along with the development of thoracic surgery, a lot of has been published about the technique, perils, and indications for pneumonectomy. This sort of surgery made great progress with endotracheal mechanical ventilation. Magill offered the possibility of excluding the ventilation of the operated side in 1935. The first double-lumen tube for thoracic surgery was introduced by Carlens. Transformation of the daily surgical practice was made by the invention of surgical staplers in 1970, developed by soviet researchers in 1960s. Eventually, the apparition of video-assisted and continuous development of minimally invasive surgery changed and divert this issue of the technological advances.

Over time indications for pneumonectomy have changed, and the first application of it is made by development of lung cancer. In modern days, pneumonectomy for inflammatory lung diseases. bronchiectasis, tuberculosis and other non-malignant conditions is not quite common. Pneumonectomy continue to be a challenging operation, bringing up many complications and anatomic and physiologic alterations.

Among all types of lung resections, pneumonectomy is the procedure with the highest morbidity and mortality. 
Table 1 Distribution of patients involved, average age, morbidity, and mortality

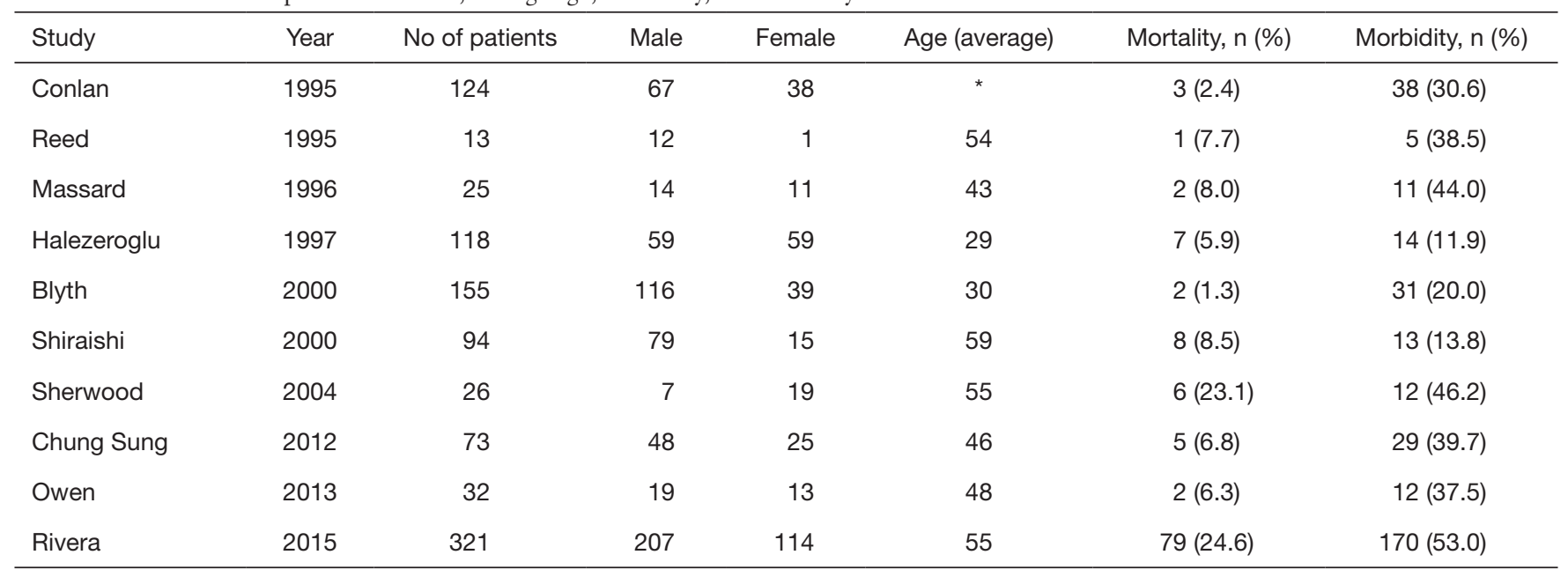

*, this study involves children and the average age is not presented for this reason, also sum of patients include only older patients without minors.

Infrequently, pneumonectomy is requisite to afford cure to patients with benign lung disease, but very challenging in the presence of the empyema. Most empyema are sequelae of the multidrug-resistant tuberculosis in severely damaged lung, disposed to repeated super infections. This damaged lung cannot expand properly, and respiratory problems caused by the destroyed lung could lead the surgeon in favorising for the pneumonectomy procedure.

The ground of this review is to present different position in literature in treating empyema by pneumonectomy, as well as to identify indications and potential indicators for intraoperative and postoperative complication. Empyema is an obsolete disease, yet it remain to be a relevant clinical issue. The meaning of empyema is "pus in the chest", the term from the Greek-épnuqpa. The most general precursors of empyema are bacterial pneumonia and parapneumonic effusion. Other reasons encompass blunt or penetrating chest trauma, mediastinitis with pleural effusion, bronchogenic carcinoma, infected congenital cyst of the airways and oesophagus, oesophageal rupture, extension from sources below the diaphragm, cervical and thoracic spine infections and postsurgical etiologies.

\section{Methods}

The authors realized a search in the PubMed database involving the subsequent strategy: ((("pneumonectomy" [Title/Abstract]) AND ((“empyema”) OR “empyema”)) AND "benign disease") AND ((“management") OR "treatment")). Just English-language articles published between January 1, 1995, and August 31, 2019 were considered. References of relevant articles were also manually searched to identify potentially eligible articles.

\section{Results}

Two hundred and seventy were found in the literature mismatch search. After a manual review of title and abstract and/or full text of each citation, the authors screened 10 accurate papers. Among these studies, the authors have chosen only the one who had empyema as results of the underlying benign disease for the reason to perform pneumonectomy.

The number of patients involved, gender distribution, average age, as morbidity and mortality rate after pneumonectomy for empyema is illustrated in Table 1

The morbidity rate and the percentage of the most common complications after pneumonectomy for empyema was depicted such as post pneumonectomy empyema (PPE) - here is percentage who is not involved with bronchial fistula, bronchial fistula (BF) and excessive bleeding as serious complication too is presented in Table 2 .

\section{Discussion}

Infected lung disease and pulmonary abscesses are the most persistent indications of pneumonectomy for non malignant reasons. Tuberculosis comes in two main forms dealt by pneumonectomy: multidrug-resistant Mycobacterium tuberculosis and post-tuberculosis destroyed lung. Non- 
Table 2 Most common complications after pneumonectomy for empyema

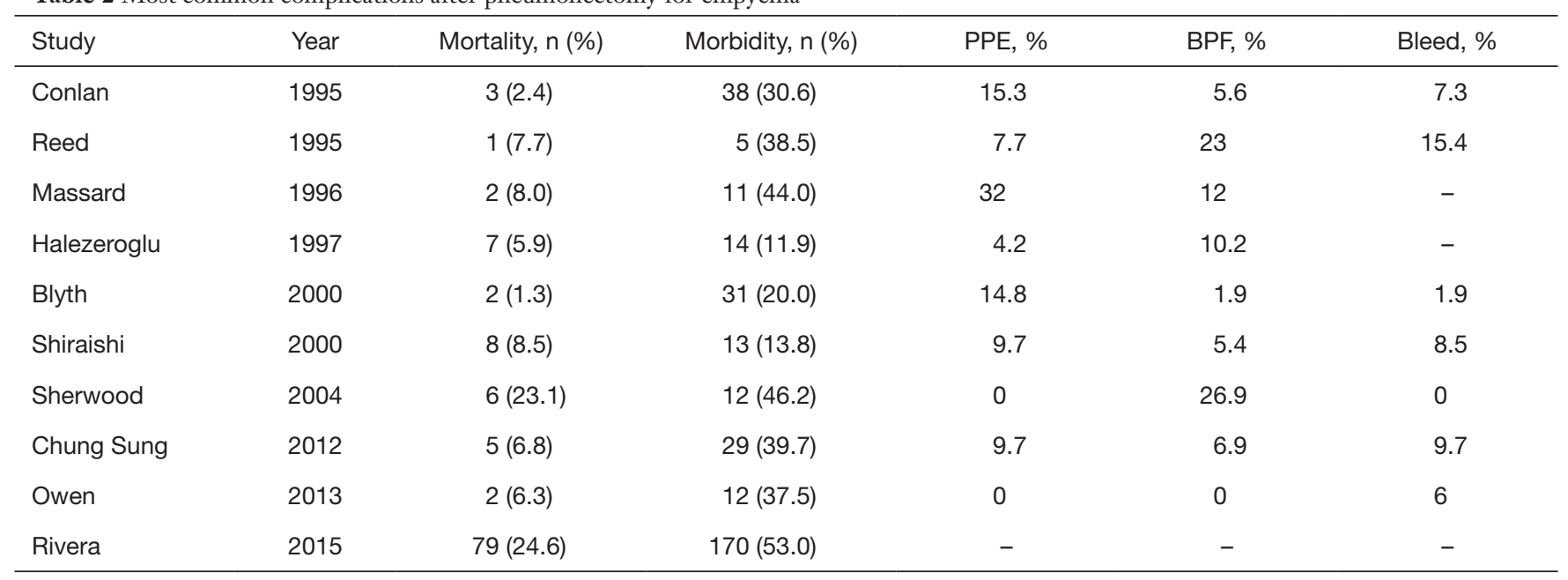

PPE, post pneumonectomy empyema; BPF, bronchopleural fistula.

malignant tumors represent $6.5 \%$ of resections, indicating that benign tumors rarely demanding pneumonectomy.

Pneumonectomy for benign disease was performed in significantly younger patients and their sex ratio is lower. Patients who need a pneumonectomy on an emergency context represent $37 \%$ of this group, and a third group was life-threatening emergencies. Obviously, these patients haven't anything with those patients who had presented for classic surgery for lung cancer, suggesting that any postponement of surgical treatment should be attempted.

Pneumonectomy for mild disease has been represented with higher morbidity and mortality than pneumonectomy for lung cancer (2). It is noted a mortality rate of $26.3 \%$ for patients sustaining pneumonectomy (PC) for benign disease, by Miller et al. (3). In comparison, Sherwood et al. (4) reported postoperative mortality of $23 \%$ for CP in patients with mycobacterial disease. Mortality rates could be comparable to pneumonectomy in patients with cancer, with prudent patient selection and meticulous surgical technique.

Several series reported morbidity rates of $33 \%$ to $50 \%$ for patients undergoing a PC for minor illnesses (3-7), but the morbidity rate from $15 \%$ to $48 \%$ is shown in several other series (8-11) which examined both CP and simple pneumonectomies in patients with the same conditions. The overall complication rate was $38 \%$ and the morbidity rate was $80 \%$ in the subgroup of patients with invasive opportunistic infections. Therefore, it could be significant in morbidity for pneumonectomy for benign diseases.

Generally, medical complications are more frequent than complications of surgery after pneumonectomy for benign disease. Medical complications occurred in 64\% in those patients, while surgical complications appeared in $20 \%$, reported by Miller et al. (3). Sirmali et al. (6) noted the most common major complications-heart arrhythmia in $17 \%$ of patients, which was twice as common as surgical complications. There was also a $16 \%$ rate of pulmonary complications, alike to the $15 \%$ rate reported by Reed (10). Nevertheless, empyema is an obsolete issue, which continue to be a challenge for thoracic surgeons. Its prevalence has decreased with the addition of antibiotic treatment for inflammatory pulmo and pleural disease. It is reported that various patients with chronic empyema were treated successfully by decortications, muscle transposition, thoracoplasty or a combination of these procedures (8-10). Despite this, all patients with empyema and lung destroyed not can be treated by lung preservation procedures, given the need for resultant resection of the underlying lung. Thus, extra pleural pneumonectomy is marked for patients who require a resection of both, empyema and the underlying lung.

Since the era of tuberculosis, an extra-pleural pneumonectomy has been employed for empyema and destroyed lung. However, a high incidence of postoperative problems correlates with this procedure. It has been reported long ago by Okano and Walkup (12), postoperative development of empyema in 17 of 30 patients, undergoing extra pleural pneumonectomy, and 9 patients had bronchopleural fistula (BF).

The case sufficiently extensive pleural disease require 
extra pleural pneumonectomy showed $21.9 \%$ mortality and empyema rate of $17 \%$ reported by Langston and his colleagues (13). Actually, the greatest prevalence of postoperative complications after pneumonectomy for destroying lung has been noted in patients with preoperative empyema. Extra pleural dissection was attempted at the beginning of the operation, but it could not be performed throughout the operation in $9.3 \%$ of patients, according to Halezeroglu and coworkers (14).

Therefore, it has been proposed that extra-pleural pneumonectomy should only be done when definitely inevitable and only in a cautiously chosen group of patients (15). Pneumonectomy through empyema, decortications and thoracomyoplasty $(16,17)$, like several alternative procedures, have been suggested to reduce the incidence of postoperative complications. Despite, pneumonectomy through an empyema results in a high rate (45.7\%) of postoperative empyema (18).

Decortications and thoracomyoplasty obliterate the empyema space, but leave the destroyed lung, which cannot improve the respiratory morbidity caused by the underlying lung. The primary goal of decortications is to employ the native lung as a "natal prosthesis" to plug the pleural space and avoid extra pleural pneumonectomy (16). In the face of these unfavorable references of extra plural pneumonectomy, when there was no other option, radical surgery should be performed in selected patients with empyema and a destroyed lung.

It is also reported that a pneumonectomy for a destroyed lung performed in patients with preoperative empyema has a 60 -day mortality of $14.8 \%$ (14). When a pneumonectomy is realized for chronic pulmonary infections, operative mortality varies $2.4 \%$ to $7.6 \%(8-10,14)$.

\section{Complications}

One of the most serious complications after an extrapleural pneumonectomy is postoperative empyema. There are many possible risk considerations for postpneumonectomy empyema (PPE). The only significant risk aspect for postoperative empyema has been shown to be reexploration for hemorrhage, making the pleural cavity more susceptible to infection; therefore, it should be avoided, with precise hemostasis before closing the chest, also adding the other techniques like continuous washing. The incidence of PPE is increased by preoperative drainage. It is noted by Langston and colleagues (13) that complications after pneumonectomy are presented probably more in patients who had had a drainage used as a preliminary step and that still had sinus tract at the time of the operation. In contrast, preoperative chest drainage and window thoracostomy slightly diminish the incidence of postoperative empyema. The prevalence of postoperative empyema increases as the pleural cavity is contaminated by infected material intraoperatively and when empyema is deliberately opened, as reported by some investigators $(8,9,12)$.

After a pneumonectomy for chronic infection, a high frequency of empyema has been reported in the event of a significant intraoperative pleural spillage $(8,9)$. Moreover, the prevalence of postoperative empyema was $45.7 \%$ in patients who underwent pneumonectomy through an empyema (18). Once empyema entered, it is suggested to regularly irrigate the pleural cavity with a large amount of saline and povidone iodine until a Gram stain and acid-fast staining of pleural fluid are negative. Careful intraoperative irrigation decrease the incidence of PPE.

It has been shown by Langston and coworkers (13) that patients who have survived extra pleural pneumonectomy have a good chance of obtaining a satisfactory result. According to their report, immediate mortality was elevated to $36 \%$, with an occurrence of empyema of $28.5 \%$ in the survivors. The results of the Shiraishi study (19) were consistent with the results of the Langston data. The operative survivors were without the signs of empyema 5 years after the operation at the rate of $89 \%$, and the operative mortality was $8.5 \%$. Hence, it is a suggestion, when necessary, the practice of an extra pleural pneumonectomy in the treatment of patients with no other options.

The series of Massard and Fujimoto $(8,20)$ showed the highest rates of PPE with a prevalence of $32 \%$ and $41 \%$, respectively. Pneumonectomy for mild disease had the lowest documented PPE rate with a prevalence of $5 \%$.

$\mathrm{BF}$ can be a major postoperative complication. Halezeroglu and colleagues (14) outlined that $22.2 \%$ of patients with a preoperative empyema generate a $\mathrm{BF}$ after pneumonectomy, apart of Shiraishi study, which reported incidence of the same complications even with a rate of $5.4 \%$. The incidence of $\mathrm{BF}$ varies from $5.6 \%$ to $23 \%$ when pneumonectomy is performed for chronic lung infection (8-10). Shiraishi's study showed the development of BF in patients only who were operated on the right side. In addition, it was marked the occurrence of $\mathrm{BF}$ is primarily in the operation of the right side after pneumontomy for lung cancer and mycobacterioses (21). This could be explained by the lack of usable natural cover for the bronchial stump on the right, so it is recommended to reinforce the 
bronchial stump with latissimus dorsi if the operation is on the right side (22). The bronchial stump on the left side is covered with a muscle flap to protect it from intraoperative contamination. The treatment of this complication requires a minimum of thoracostomy tube for drainage, but often reoperation for debridement and closure of a $\mathrm{BF}$.

According to the data, the key to avoiding PPE and $\mathrm{BF}$ depends on the proper management of preoperative patients, precise surgical technique and offensive supervision of the pleural space. Preoperative antibiotics are imperative in case of recorded infections. Preoperative treatment for Mycobacter I infection consists of multi-drug regimens lasting at least 2 to 3 months, before surgery. The management of the bronchial stump is of the utmost importance and it should prevent formation of BF. The bronchial stump should be split flush with the carina, and minimal peri-bronchial dissection should be performed to maintain the vascularity and stimulate recovery. The need for additional coverage of muscle flap of the bronchial stump to cope with mycobacterial infections is emphasized, by Pomerantz (21).

The BF may still develop despite the cover of the bronchial stump, especially in the presence of an infection. As a rule, it is recommended the irrigation of the pleural space with a solution containing antibiotics in infected cases, the continuation and obliteration of the pleura space with muscle and omental transposition along the thoracoplasty, in the event of massive pleural contamination. Therefore, it is favorable approach of creating a Eloesser thoracostomy with closing delay of the chest cavity with a Claggett procedure, in cases of controlled pleural sepsis and physiologically optimized patient.

A risk of massive intraoperative bleeding is carried by pneumonectomy for benign diseases. Hilar dissection is extremely difficult in the presence of inflammatory tissue and dense adhesions. Intrapericardial control of the hilar structures is often a safe way to yield. It is described by Mansour, that hilar dissection should be started backwards with the division of the bronchi first to allow better access to the hilar vascular structures. In addition, extensive pneumolysis and extra-pleural dissection set a hazard of prolonged bleeding in the postoperative course. We would personally advice the anterior approach to control pulmonary artery and veins intrapericardialy and then performing pneumonectomy after a vessels and bronchus control. We could advice also to use one additional second small thoracotomy for adhesiolysis if it's necessary

\section{Conclusions}

Pneumonectomy for benign disease if performed for a variety of indications, and it is a high-risk procedure. Patients with mild conditions should have higher long-term survival correlated with those with malignancy. Particularly poor prognostic groups present patients with invasive opportunistic infections. Therefore, this procedure should be appraised as a treatment alternative for carefully selected patients.

For surgeons, it is a real professional defiance facing the condensed scar tissue and inflammatory adhesions around the vessels, making very hard hilar dissection with prolonged operating time. In addition, it can be difficult to identify the gap in the pleural cavity, compelling the surgeon to dissect extrapleurally, triggering significant blood loss and risking postoperative hemothorax.

Some factors can influence postoperative hospital mortality. According to $\mathrm{Hu}$ et al. (23) a separate risk aspect for major complications after pneumonectomy in patients with a benign lung disease could be the operating time. The French study (24) showed that emergency was the only variable having a significant impact on post-operative mortality.

Hemostasis infection was the most common indication of life-threatening emergencies. Pneumonectomy for benign disease in an emergency context should be limited to patients in whom there is no alternative but resection.

In summary, an extra pleural pneumonectomy for empyema should be performed in selected patients, with a reasonably acceptable morbidity and mortality. Postoperative empyema should be avoided and it contributes to a poor prognosis. Reinforcement of the bronchial stump with muscle flaps is recommended, especially on the right side.

\section{Acknowledgments}

We acknowledge to our teachers and older colleagues Prof. Dr. Dragan Subotic, Belgrade, and Prof. Dr. Christophe Peillon, Rouen, for time spend with us in surgery, comprehending together the state of art in the most challenging cases in thoracic surgery especially in the most difficult cases like different forms of pneumonectomies including those with empyema. Also we give gratitude to Dr. Lorenzo Spaggiari, and Dr. Luca Bertolaccini who gave us this demanding topic which we present in this review.

Funding: None. 


\section{Footnote}

Provenance and Peer Review: This article was commissioned by the Guest Editors (Lorenzo Spaggiari and Luca Bertolaccini) for the series "The Role of Pneumonectomy in Thoracic Surgery in The Third Millennium" published in Shanghai Chest. The article has undergone external peer review.

Conflicts of Interest: Both authors have completed the ICMJE uniform disclosure form (available at http:// dx.doi.org/10.21037/shc-20-62). The series " The Role of Pneumonectomy in Thoracic Surgery in The Third Millennium" was commissioned by the editorial office without any funding or sponsorship. The authors have no other conflicts of interest to declare.

Ethical Statement: The authors are accountable for all aspects of the work in ensuring that questions related to the accuracy or integrity of any part of the work are appropriately investigated and resolved.

Open Access Statement: This is an Open Access article distributed in accordance with the Creative Commons Attribution-NonCommercial-NoDerivs 4.0 International License (CC BY-NC-ND 4.0), which permits the noncommercial replication and distribution of the article with the strict proviso that no changes or edits are made and the original work is properly cited (including links to both the formal publication through the relevant DOI and the license). See: https://creativecommons.org/licenses/by-nc-nd/4.0/.

\section{References}

1. Waters PF. Pneumonectomy. In: Pearson FG, Hiebert CA, Deslauriers J, et al. editors. Thoracic surgery. New York: Churchill Livingstone Inc., 1995:844-8.

2. Shapiro M, Swanson S, Wright CD, et al. Predictors of major morbidity and mortality after pneumonectomy utilizing the society for thoracic surgeons general thoracic surgery database. Ann Thorac Surg 2010;90:927-34; discussion 934-5.

3. Miller DL, Deschamps C, Jenkins GD, et al. Completion pneumonectomy: factors affecting operative mortality and cardiopulmonary morbidity. Ann Thorac Surg 2002;74:876-83; discussion 883-4.

4. Sherwood JT, Mitchell JD, Pomerantz M. Completion pneumonectomy for chronic mycobacterial disease. J
Thorac Cardiovasc Surg 2005;129:1258-65.

5. Jungraithmayr W, Hasse J, Olschewski M, et al. Indications and results of completion pneumonectomy. Eur J Cardiothorac Surg 2004;26:189-96.

6. Sirmali M, Karasu S, Gezer S, et al. Completion pneumonectomy for bronchiectasis: morbidity, mortality and management. Thorac Cardiovasc Surg 2008;56:221-5.

7. al-Kattan K, Goldstraw P. Completion pneumonectomy: indications and outcome. J Thorac Cardiovasc Surg 1995;110:1125-9.

8. Conlan AA, Lukanich JM, Shutz J, et al. Elective pneumonectomy for benign lung disease: modernday mortality and morbidity. J Thorac Cardiovasc Surg 1995;110:1118-24.

9. Massard G, Dabbagh A, Wihlm JM, et al. Pneumonectomy for chronic infection is a high-risk procedure. Ann Thorac Surg 1996;62:1033-7; discussion 1037-8.

10. Reed CE. Pneumonectomy for chronic infection: fraught with danger. Ann Thorac Surg 1995;59:408-11.

11. Ashour M. Pneumonectomy for tuberculosis. Eur J Cardiothorac Surg 1997;12:209-13.

12. Okano T, Walkup HE. Some problems in extrapleural pneumonectomy for tuberculous empyema and destroyed lung. J Thorac Surg 1958;35:523-31.

13. Langston HT, Barker WL, Graham AA. Pleural tuberculosis. J Thorac Cardiovasc Surg 1967;54:511-9.

14. Halezeroglu S, Keles M, Uysal A, et al. Factors affecting postoperative morbidity and mortality in destroyed lung. Ann Thorac Surg 1997;64:1635-8.

15. Mouroux J, Maalouf J, Padovani B, et al. Surgical management of pleuropulmonary tuberculosis. J Thorac Cardiovasc Surg 1996;111:662-70.

16. Massard G, Rougé C, Wihlm JM, et al. Decortication is a valuable option for late empyema after collapse therapy. Ann Thorac Surg 1995;60:888-95.

17. García-Yuste M, Ramos G, Duque JL, et al. Open-window thoracostomy and thoracomyoplasty to manage chronic pleural empyema. Ann Thorac Surg 1998;65:818-22.

18. Odell JA, Buckels NJ. Techniques of pneumonectomy: pneumonectomy through an empyema. Chest Surg Clin N Am 1999;9:369-78.

19. Shiraishi Y, Nakajima Y, Koyama A, et al. Morbidity and mortality after 94 extrapleural pneumonectomies for empyema. Ann Thorac Surg 2000;70:1202-6; discussion 1206-7.

20. Fujimoto T, Zaboura G, Fechner S, et al. Completion pneumonectomy: current indications, complications, results. J Thorac Cardiovasc Surg 2001;121:484-90. 
21. Pomerantz M, Madsen L, Golbe M, et al. Surgical management of resistant mycobacterial tuberculosis and other mycobacterial pulmonary infections. Ann Thorac Surg 1991;52:1108-11.

22. Pairolero PC, Arnold PG, Piehler JM. Intrathoracic transposition of extrathoracic skeletal muscle. J Thorac Cardiovasc Surg 1983;86:809-17.

doi: $10.21037 /$ shc-20-62

Cite this article as: Kostic M, Baste JM. Pneumonectomy for empyema. Shanghai Chest 2021;5:20.
23. Hu XF, Duan L, Jiang GN, et al. Risk factors for early postoperative complications after pneumonectomy for benign lung disease. Ann Thorac Surg 2013;95:1899-904.

24. Rivera C, Arame A, Pricopi C, et al. Pneumonectomy for benign disease: indications and postoperative outcomes, a nationwide study. Eur J Cardiothorac Surg 2015;48:435-40. 